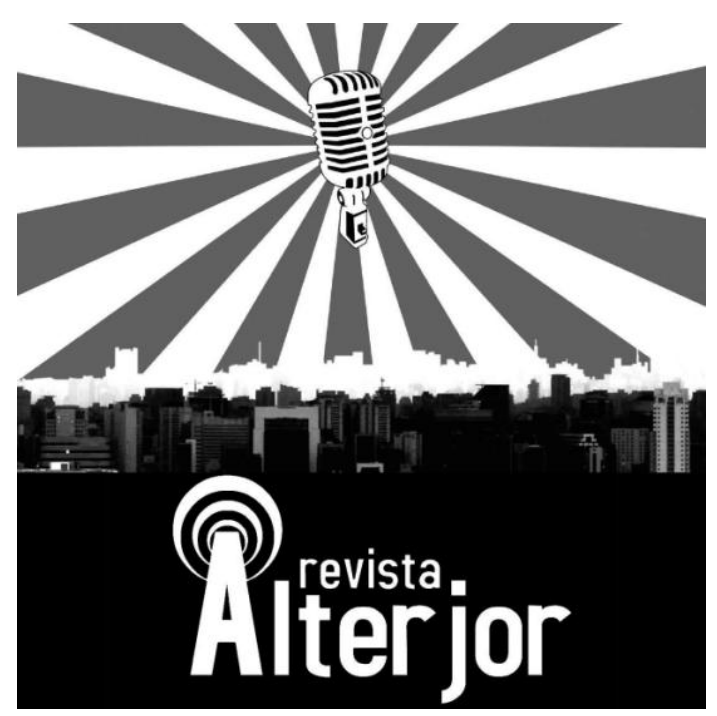

DOSSlê: "Comunicação nas Periferias"

\title{
O CUSTO DA NOTÍCIA: AS RELAÇÕES DE TRABALHO E ESTABILIDADE FINANCEIRA DOS COLETIVOS DE JORNALISMO DA PERIFERIA DE SÃO PAULO ${ }^{1}$
}

\author{
Caroline Pasternack Pereira dos Santos ${ }^{2}$
}

RESUMO: O artigo a seguir busca entender como acontecem as relações de trabalho e o financiamento entre os coletivos de jornalismo alternativo e seus colaboradores. O recorte da pesquisa são coletivos da periferia de São Paulo. Para procurar encontrar dados que nos auxiliem a responder e debater o assunto, escolhemos a Agência Mural, que cobre o cotidiano das periferias da capital paulista e da região metropolitana. Buscamos, através de entrevistas com alguns integrantes, entender como acontece essas relações de trabalho e como está a estabilidade e saúde financeira desses veículos.

PALAVRAS-CHAVE: Jornalismo alternativo. Relações de trabalho, Estabilidade financeira. Periferia. Jornalismo de periferia.

ABSTRACT: The following article intends to understand how working relations and funding happen between alternative journalism collectives and their collaborators. The research is carried out by collectives from the periphery of São Paulo. In order to find data to help us answer and debate the subject, we have chosen Agência Mural, which covers the daily life of the peripheries of São Paulo and the metropolitan region. Through interviews with some members, we sought to understand how these working relationships happen and how the stability and financial health of these vehicles are.

KEYWORDS: Alternative journalism. Working relations. Financial stability. Periphery. Periphery journalism.

\footnotetext{
${ }^{1}$ Esse artigo é parte da pesquisa que resultou na dissertação "Traços de hegemonia no alternativo: o caso da Agência Mural", defendida em 26/06/2020 no Mestrado Profissional de Jornalismo do FIAM FAAM Centro Universitário, com bolsa de estudos institucional, sob orientação do Prof. Dr. Ivan Paganotti.

2 Mestra em jornalismo pelo Mestrado Profissional de Jornalismo do FIAM FAAM - Centro Universitário com a pesquisa sobre jornalismo feito pela periferia. Também atuou como colaboradora no coletivo Agência Mural. E-mail: caroline.pasternack@gmail.com
}

\section{Revista ALTERJOR}

Grupo de Estudos Alterjor: Jornalismo Popular e Alternativo (ECA-USP)

Ano 10 Volume ol Edição 23 Janeiro-Julho de 202l

Avenida Professor Lúcio Martins Rodrig̉ues, 443, Cidade Universitária, São Paulo, CEP: 05508-020 


\section{INTRODUÇÃO}

Com esse artigo, pretendemos discutir como funcionam algumas das relações de trabalho e estabilidade financeira de coletivos na cidade de São Paulo. Para isso, fizemos um recorte ao escolher veículos que atuem na periferia da capital paulista. Ainda no recorte, trataremos de um coletivo em específico: a Agência Mural de Jornalismo das Periferias, que pretende realizar uma cobertura sem estereótipos sobre as margens da cidade e da região metropolitana de São Paulo.

Falar de jornalismo alternativo hoje nos remete a diversas épocas, classificações e os mais variados modelos, desde empresas que contratam seus jornalistas como funcionários CLT, até coletivos que seguem o modelo horizontal e buscam confrontar conglomerados de mídia ou questionar modelos ditos como hegemônicos. Se começarmos pelas definições mais clássicas, acabaremos por citar seus primórdios: o nascimento de diversas mídias durante a ditadura militar.

Nascida na década de 1970, a imprensa alternativa, por meio de diversos periódicos, buscava um único objetivo:

A imprensa alternativa surgiu da articulação de duas forças igualmente compulsivas: o desejo das esquerdas de protagonizar as transformações que propunham e a busca, por jornalistas e intelectuais, de espaços alternativos à grande imprensa e à universidade. [...] Compartilhavam, em grande parte, um mesmo imaginário social, ou seja, um mesmo conjunto de crenças, significações e desejos, alguns conscientes e até expressos na forma de uma ideologia, outros ocultos, na forma de um inconsciente coletivo (KUCINSKI, 2001, p.6).

A expressão "imprensa alternativa" foi usada pela primeira vez no Brasil, em 1976, por Alberto Dines, em sua coluna de crítica à cobertura da mídia, no jornal Folha de S. Paulo (KUCINSKI, 1998 apud SANTOS, 2013)

\footnotetext{
Surgiu de uma tradução literal do inglês "alternative press", num momento em que "alternativo" já era utilizado nos Estados Unidos e na Inglaterra para designar arte e cultura não convencionais. No caso, Dines fazia referência à imprensa brasileira que surgiu como oposição à ditadura militar que vigorou no Brasil entre 1964 e 1985 e à forte censura por ela imposta, até então chamada de "imprensa nanica", "popular", entre outras acunhas (SANTOS, 2013, p. 83).
} 
Cinquenta anos depois, a motivação política ainda existe, mas hoje divide cenário com muitos outros agentes que buscam a transformação por meio do jornalismo, como vozes que não eram ouvidas, mais liberdade de opinião, matérias que fogem do 'hard news' diário, encontrar soluções para seus bairros, mais diversidade nas redações, entre outros. O jornalismo alternativo hoje não espera mais o aval da grande mídia para expor sua voz. E o melhor, também pauta essas grandes mídias.

Saindo da década de 1970 e ficando mais próximo dos nossos dias, encontramos na popularização do uso da internet, em meados dos anos 2000, outros fatos que resultaram em diversos movimentos midiáticos que temos hoje. A migração de diversos profissionais para o ambiente da blogosfera, foi um deles, pois proporcionou o nascimento de diversos veículos que continuam até hoje e também abriu caminho para outros que viriam. "No blog, o jornalista escreve sobre o que gosta, assume integralmente o papel de formador de opinião, com a possibilidade de aprofundar a notícia" (NONATO, 2018, p. 7).

\section{A INTERNET COMO MOTOR DE MANIFESTAÇÕES}

Além das transformações dos meios, a sociedade também mudou. Após as manifestações de $2013^{3}$, o descrédito com a chamada mídia tradicional atingiu seus maiores números e quem estava na rua cobrava por uma cobertura que de fato mostrasse os problemas do país e o que estava acontecendo nas manifestações. Loureiro e Casadei (2019) em seu estudo "Isso a Globo não Mostra: dimensões afetivas das notícias falsas no debate sobre o descrédito da imprensa tradicional", investigaram "os afetos sociais envolvidos no descrédito da grande mídia como fonte legitimada de informações e sua relação com a difusão de notícias falsas”. Em seu artigo de apresentação, as pesquisadoras citam dados que ajudam a entender esse descrédito.

[..]os meios de comunicação caíram $28,17 \%$ no índice de confiança nas instituições (pesquisa realizada pelo Ibope Inteligência) no último ano, comparado ao número de 2009; de 2017 em comparação a 2018, a queda foi

\footnotetext{
3 Manifestações que aconteceram em junho de 2013 motivadas pelo aumento nas tarifas de ônibus municipais, mas acabou motivando a manifestação de outras demandas em falta no país como saúde e educação.
} 


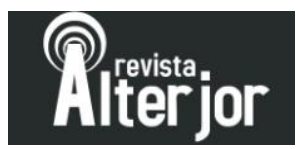

ainda maior: de 10 pontos percentuais. Os sinais de descrença na mídia pela opinião pública no Brasil ficaram manifestos nas movimentações de 2013, as jornadas de junho, quando os repórteres presentes foram hostilizados e surgiu o fenômeno da Mídia Ninja. No Trust Barometer 2018, pesquisa desenvolvida anualmente pela empresa global de Relações Públicas Edelman, pela primeira vez a mídia (que engloba produtores de conteúdo e plataformas) é considerada a instituição menos confiável globalmente (LOUREIRO; CASADEI, 2019).

É nesse momento histórico que diversas mídias alternativas se destacam. De acordo com Carvalho e Bronosky (2017), a migração midiática dos veículos tradicionais brasileiros, das plataformas de TV, rádio e impresso para a internet, e a incapacidade da mídia hegemônica de transmitir e responder às demandas sociais, seja pela cobertura dos fatos ou pela imposição dos interesses privados, veio em conjunto com a facilidade da criação de iniciativas de baixo custo, com terreno digital, resultando em novos veículos alternativos.

[...] o jornalismo alternativo ganha terreno no Brasil, apostando na segmentação do público e na especialização sobre determinados temas. Com uma estrutura mais fluída do que as das grandes empresas jornalísticas, os alternativos apresentam-se como opção não apenas para quem acessa seus conteúdos, mas também para quem faz jornalismo. (CARVALHO; BRONOSKY, 2017, p. 22 e 23).

Em 2013, diversos veículos alternativos surgem com a bandeira de oferecer informações desassociadas de interesses comerciais e políticos como Mídia Ninja, Jornalistas Livres, Agência Pública e Ponte Jornalismo, com nomes que sugerem uma saída do comum, do privado, dos interesses. Ainda que outros coletivos já existissem nessa época, o surgimento de tantas iniciativas jornalísticas abre terreno para que outros jornalistas também mostrem suas vozes. De acordo com o Mapa da Pública levantamento realizado pela Agência Pública, realizado entre 2015 e 2016, existem 79 veículos alternativos\ independentes em atividade no Brasil (AGÊNCIA PÚBLICA, 2016).

O levantamento também visava analisar, quantificar e avaliar como essas iniciativas que não faziam parte dos conglomerados de mídia conseguiam se manter nesses outros tipos de mídia, também chamados de arranjos econômicos. O conceito "arranjos econômicos" foi criado pelos pesquisadores do CPCT-ECA/USP durante 


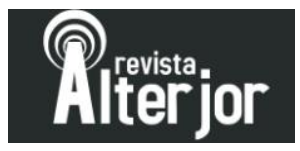

pesquisa para analisar a migração dos jornalistas da grande mídia para outros modelos, em busca de viabilidade financeira e também de permanência na carreira.

\section{ALTERNATIVOS E PERIFÉRICOS}

A pesquisa "As relações de comunicação e as condições de produção no trabalho de jornalistas em arranjos econômicos alternativos às corporações de mídia" (FÍGARO, 2018), realizada pelo CPCT-ECA/USP, entre os anos de 2016 e 2018, realizou um intenso levantamento sobre como os coletivos, inclusive os periféricos, se mantém economicamente e como organizam sua produção.

Algumas conclusões obtidas pelos pesquisadores, após entrevistas com 26 jornalistas responsáveis por diferentes arranjos econômicos, trazem à tona contestações que reforçam o debate sobre as complicações enfrentadas pelos veículos alternativos ao mesmo tempo em que buscam realizar um jornalismo que se distancie dos interesses comerciais da grande mídia.

A pesquisa demonstra que o trabalho em alguns desses arranjos é precarizado, muitas vezes voluntário e sem a certeza de quando receberão por suas atividades desenvolvidas. Há também a intensificação do trabalho, já que muitos dos jornalistas precisam manter seus empregos em outros locais, ou através de outros freelas, para obter uma renda e, após isso, dedicar-se ao seu trabalho no arranjo, desempenhando uma dupla função (FÍGARO, 2018).

Os coletivos ou arranjos que conseguem se manter sem a necessidade de outras rendas ainda são poucos e sua receita não advém da produção jornalística que realizam, mas de outras rendas como editais da prefeitura, venda de serviços ou aportes de fundações como a Fundação Ford e a Open Society, e financiamentos recorrentes, no estilo crowdfunding (FÍGARO, 2018).

A situação fica ainda mais difícil quando falamos de jornalismo periférico, com jornalistas que vêm das margens das cidades e precisam de mais segurança econômica para se manterem. O Projor - Instituto para o Desenvolvimento do Jornalismo - 


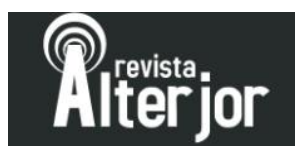

desenvolveu, em parceria com o Volt Data Lab o "Atlas da Notícia"4, levantamento inédito com base em jornalismo de dados sobre a presença ou ausência da imprensa em todo o território nacional. Os dados mostraram que existem "desertos de notícias, ou seja, aproximadamente 4.500 municípios no país sem jornais ou sites de notícias no Brasil.

Os números representam, segundo a pesquisa, mais de 70 milhões de habitantes sem nenhum veículo de notícias. As periferias são parte desse deserto, apesar de reunir uma grande parcela da população nacional, e influenciar comportamentos e movimentos culturais que acabam por ser apropriados pela classe dominante e cultura mainstream. (NONATO, 2018).

E não é só a distância territorial do centro com a periferia que afasta a criação de mídia, mas também a distância cultural, intelectual, econômica e de oportunidades. Quem chega às redações são pessoas de classe média e alta, que podem receber salários baixos ou realizar estágios, muitas vezes sem remuneração, pois contam com o auxílio da família para esperar pelo momento de ser de fato contratado.

De acordo com Nonato (2018), em sua pesquisa "O perfil do jornalista das periferias de São Paulo: resultados iniciais”, feita com jornalistas que produzem jornalismo na periferia em coletivos, "a maioria dos respondentes é do sexo feminino, da raça branca e já possui pessoas graduadas na família, fato que, de certo modo, reproduz o perfil dos jornalistas que trabalham nas redações da grande mídia " (Nonato, 2018, p. 12).

Como quem produz o jornalismo não vive algumas realidades, certos assuntos são negligenciados dentro da grande mídia, tornando o terreno para o jornalismo alternativo ainda mais fértil, como no caso das mídias alternativas periféricas. Segundo Carvalho e Bronosky:

As iniciativas de jornalismo alternativo se aproximam a grupos sociais que geralmente se apresentam como opositores à ordem vigente, como é o caso de movimentos sociais. Dentre os aspectos que contribuem para isso estão as concepções ideológicas relativamente distintas as da mídia hegemônica, tanto

\footnotetext{
${ }^{4}$ Disponível em https://www.atlas.jor.br/. Acesso em 21/09/2019. 
pela decisão de pautas de interesse público como pelo modo de produção, entre outros fatores (CARVALHO, BRONOSKY, 2017, p. 25).

É nessa insatisfação com a grande mídia e por sua incapacidade de trazer as informações das margens ao público de uma maneira desteriotipada que nasce e cresce a participação de jornalistas e profissionais de comunicação em iniciativas jornalísticas alternativas aos conglomerados e empresas de mídia, que se autodenominam coletivos de jornalismo.

Como representante de $30 \%$ do mercado jornalístico brasileiro, a cidade de São Paulo é conhecida como um dos principais polos de surgimento das mídias alternativas. Assis et al. (2017) diz que o termo "indies" (abreviação para independents) também é associado a projetos digitais inovadores, organizações sem fins lucrativos, ou ainda, veículos de comunicação "subversivos" ou contrários ao "sistema”. Porém, Assis et al. (2017) apud Hunter (2015) aponta que "a natureza precária do trabalho independente, assim como a falta de estrutura para executar o trabalho, deixa os indies tão ou mais vulneráveis a pressões externas e outros interesses do que os jornalistas formalmente empregados".

A precarização da área também atinge os coletivos e veículos independentes, que tentam recorrer a diversos tipos de financiamento para se manterem e continuarem com suas propostas iniciais de jornalismo contra-hegemônico.

\section{METODOLOGIA}

Para entender as relações de trabalho e a sustentabilidade financeira em coletivos, decidimos analisar um dos que realiza cobertura na cidade de São Paulo, a Agência Mural. O método escolhido para levantar dados que nos ajudaram a debater o assunto foi a entrevista com membros do coletivo, que irão nos ofereceram dados sobre suas rotinas, métodos, linha editorial, escolha de pautas, entre outros dados que nos ajudarão a responder como se dão essas relações. 


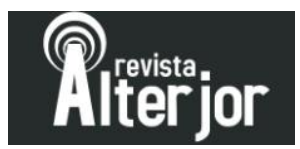

A Agência Mural surgiu em 24 de novembro de 2010, inicialmente como blog Mural, "o primeiro blog de notícias das periferias de São Paulo", de acordo com a própria definição do veículo.

A primeira agência de notícias, de informação e de inteligência sobre as periferias de São Paulo", criada para produzir notícias e reportagens que se propõem a incentivar a transformação social e a valorizar as histórias e acontecimentos de 96 distritos e outras 39 cidades que compõem a região metropolitana de São Paulo (SILVA, 2018, p. 67).

Hospedado desde seu início entre a lista de blogs da Folha de S.Paulo, “trocamos conteúdo exclusivo de áreas invisíveis à redação do jornal e aos seus leitores pelo direito de estar ali".

O codiretor da Agência Mural, Anderson Menezes, disse em entrevista ao Projeto Draft (INFANTE, 2019) que os primeiros dois anos de parceria com a Folha de S. Paulo foram totalmente voluntários, só após esse período que os colaboradores passaram a receber pelas matérias.

De acordo com a seção "Sobre" do site da Agência Mural, as periferias têm ficado de fora da "cobertura de boa qualidade" ou sido mal representadas através de relatos de violência, pobreza, algumas atrações culturais e só realmente chegam à mídia quando situações como uma greve de ônibus impossibilita os trabalhadores de chegarem aos bairros do centro (SILVA, 2018).

Em novembro de 2015, foi lançado o site da Agência Mural, e assim eles também passaram a se apresentar, como uma agência de notícias. A agência acoplaria todos os outros projetos do coletivo, como parcerias com mídias e entidades, que viabilizavam a parte financeira.

\begin{abstract}
Percebemos que estávamos fazendo um trabalho consistente há um bom tempo. E se estávamos fazendo de graça, já era hora de pensar em como nos sustentar com isso". Naquele momento, apenas quem produzia conteúdo para o Blog Mural era remunerado. Toda a estrutura formada para viabilizar o projeto trabalhava de forma voluntária (MENEZES apud INFANTE, 2019).
\end{abstract}

Escolhermos as entrevistas com os colaboradores da Agência Mural, pois, de acordo com Haguette (1997, p. 86) a entrevista é um "processo de interação social entre 
duas pessoas na qual uma delas, o entrevistador, tem por objetivo a obtenção de informações por parte do outro, o entrevistado".

\begin{abstract}
A entrevista como coleta de dados sobre um determinado tema científico é a técnica mais utilizada no processo de trabalho de campo. Através dela os pesquisadores buscam obter informações, ou seja, coletar dados objetivos e subjetivos. Os dados objetivos podem ser obtidos também através de fontes secundárias tais como: censos, estatísticas, etc. Já os dados subjetivos só poderão ser obtidos através da entrevista, pois que, eles se relacionam com os valores, às atitudes e às opiniões dos sujeitos entrevistados (BONI, QUARESMA, 2005 p. 72).
\end{abstract}

Duarte (2004, p.215), define que "entrevistas são fundamentais quando se precisa/deseja mapear práticas, crenças, valores e sistemas classificatórios de universos sociais específicos, mais ou menos bem delimitados, em que os conflitos e contradições não estejam claramente explicitados". Ele também salienta que a entrevista não é obrigatória em pesquisas qualitativas, como pode ficar subentendido, e sim uma das várias técnicas disponíveis ao pesquisador.

Com isto em mente, acreditamos que entrevistar os membros do coletivo, que o vivem diariamente e estão inseridos nesse universo, seria a melhor maneira de chegar aos resultados que esperamos conseguir. Porém, além de definir e escolher o uso da entrevista, é importante definir como elas serão feitas. Para realizar as conversar com os integrantes da Agência Mural, usamos um questionário semiestruturado.

A entrevista com questionário semiestruturado é uma boa escolha, pois balanceia as duas partes ruins dos questionários abertos ou fechados/estruturados. $\mathrm{O}$ aberto, que deixa o entrevistado discorrer sobre um tema, sem roteiro, pode fazer com que ele saia do assunto e seja mais trabalhoso trazê-lo de volta, o que acaba gastando muito tempo da entrevista. E o fechado, coloca questões totalmente rígidas e que pode impossibilitar o entrevistador de voltar à alguns tópicos, caso ele não tenha entendido da primeira vez (DUARTE, 2004).

Outro método a ser definido é como escolher a amostra. Para selecionar os integrantes que foram entrevistados nessa pesquisa, escolhemos a amostragem não probabilística "por conveniência", que é quando o pesquisador seleciona os participantes da pesquisa pela facilidade de acesso. A seleção dos entrevistados levará em consideração uma mescla de regiões da cidade de São Paulo e região metropolitana 


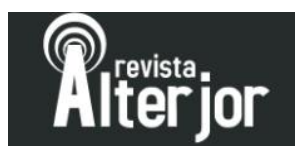

(locais que a Agência Mural atua), tempo de participação no coletivo, desde recémchegados até pessoas que estão desde o início, cargos e gênero. Nosso objetivo era alcançar $10 \%$ de integrantes. Atualmente, a Agência Mural, de acordo com seu site, possui $51^{5}$ colaboradores, então, nossa proposta foi entrevistar cinco jornalistas.

Também tínhamos o objetivo de obter uma amostra mescla e representativa, por isso dividimos homens, mulheres e regiões. Da mostra total, tínhamos 21 homens e 30 mulheres. Desse número, seis da zona sul, sete da zona leste, um da zona sul, dez da zona norte e 15 da Grande São Paulo. Com base nesses dados, escolhemos um integrante de cada região, mesclando gênero e tempo no coletivo. Para o resultado final temos: uma integrante feminina da zona leste (entrevistada E); uma integrante da Grande São Paulo (Entrevistada D); uma integrante da zona norte (entrevistada C); uma integrante da zona sul (Entrevistada A) e um integrante da zona oeste (Entrevistado B).

Foi questionado aos participantes temas como organização do coletivo, produção de pautas, temas, hierarquias, remuneração, como eles enxergavam o mercado em que estão inseridos, como classificam o próprio coletivo. Todas essas questões nos ajudaram a traçar um pequeno panorama da situação desses jornalistas em coletivos e arranjos alternativos aos conglomerados de mídia, mais necessariamente, na periferia.

Foi perguntado aos cinco entrevistados como era a organização do coletivo, se havia hierarquia e como ela era formada. Como era a rotina de produção, desde o momento da aprovação da pauta, até a publicação da notícia, entendendo melhor como funciona a rotina do coletivo e também suas particularidades.

\section{ANÁLISE DOS RESULTADOS}

Sobre a questão da hierarquia, o entrevistado B responde que no início todos colaboravam com os textos e uma pessoa era responsável pela revisão e edição, mas com o tempo, e o aumento da produção, foi necessária a criação de uma Comissão Editorial, que além de editar os textos, analisa se as pautas sugeridas pelos correspondentes estão alinhadas com as diretrizes do veículo:

\footnotetext{
${ }^{5} \mathrm{Na}$ época da dissertação. 
Um processo que começou muito mais horizontal, com todos os correspondentes e um ou outro editor, avançou para a comissão editorial e hoje temos o trabalho da equipe fixa. Hoje o trabalho funciona com a gente conversando com os muralistas, sabendo o que acontece nos bairros, recebendo sugestões de pauta e a partir daí nós tentamos orientar e auxiliar até que saia a publicação (entrevistado B).

A entrevistada E explica que as coisas mudaram após o coletivo receber o financiamento e se tornar uma empresa:

\begin{abstract}
Quando eu entrei na Mural não tinha isso muito definido. Tínhamos nós, os correspondentes e tinha a comissão editorial, que era um grupo de pessoas que estava há mais tempo na Mural. Acho que depois do financiamento teve uma nova configuração, que aí acho que ficou mais hierárquico, embora não seja aquela hierarquia de obediência e de verticalidade de decisões [...] (entrevistada E).
\end{abstract}

A escolha desse modelo pelo coletivo pode demonstrar sinais de afastamento do modelo alternativo, assim como o entrevistado B fala acima, de que havia um modelo horizontal no início. A criação de uma equipe fixa pode beneficiar e concretizar uma relação mais segura economicamente entre os colaboradores e o coletivo, entretanto, a equipe fixa é composta apenas por alguns dos integrantes, segundo o site da Agência Mural, são 14. Os outros 54 são denominados como correspondentes, que recebem por texto, o que acaba não trazendo uma estabilidade financeira para esses colaboradores.

De acordo com Anderson, um dos cofundadores, a agência não tem dono, e sim uma gestão compartilhada, com colaboradores que participam ativamente das atividades e responsabilidades do coletivo (INFANTE, 2019).

A entrevistada A traz uma visão diferente de como foi sua vivência no período que ficou na Agência Mural e sua opinião sobre a estrutura do coletivo:

Eu acho que o maior desafio de qualquer veículo de comunicação é encontrar um balanço né? Entre ser uma empresa e ser um veículo de comunicação que tem sua linha editorial com seus ideais e tem sua ideia de mundo, do que ser um veículo significa, então eu acho que por ser uma coisa nova, me passava uma impressão de que a visão empresarial ainda não estava muito amadurecida. Mas ao mesmo tempo eu percebia que existia um esforço para isso, mas é muito difícil querer ter essa questão empresarial amadurecida e bem resolvida sem ter um espaço físico, então tudo da Mural era bastante abstrato para mim e muito distante, justamente por não estar dividindo o mesmo ambiente das pessoas, com uma frequência maior. Eu acho que uma 
reunião por mês, com todo mundo lá não era suficiente para render tudo que você tem para render, tanto no individual, como no coletivo (entrevistada A).

A última fala, da entrevistada $\mathrm{A}$, traz algumas problemáticas de organização que, ao mesmo tempo que se declara como coletivo, realiza ações mais próximas de uma organização jornalística e, como a ex-integrante comenta, ainda busca o caminho da dualidade em alguns aspectos organizacionais. Apesar de ter apenas um encontro mensal, a Agência Mural possui uma equipe fixa de jornalistas, o que traz agilidade às pautas e faz caminhar a produção, entretanto, continua um pouco distante para os colaboradores não fixos. Realiza algumas exigências de contribuição, mas não oferece uma contrapartida na mesma linha. Como comenta Hunter (2015 apud Assis et al. 2017) "a natureza precária do trabalho independente, assim como a falta de estrutura para executar o trabalho, deixa os indies tão ou mais vulneráveis a pressões externas e outros interesses do que os jornalistas formalmente empregados".

- A entrevistada A comentou que a Agência Mural era apenas um complementa em sua renda, o que continuou assim pelo decorrer do ano em que foi colaboradora. Há época ela dava aulas de inglês e atualmente é recepcionista bilíngue.

- O entrevistado B, que é editor da Agência Mural, é o único dos entrevistados que se mantêm inteiramente com o coletivo, justamente por integrar a equipe fixa. Após colaborar por sete anos com o veículo dividindo o tempo livre de seu emprego que proporcionava sua renda, desde junho de 2018, após o coletivo receber financiamento, passou a ser editor em tempo integral.

- A entrevistada $\mathrm{C}$ comenta que quando produzia o coletivo chegou a ser sua fonte de renda, mas hoje não é mais. Ela também já participou de outro coletivo e foram nessas épocas em que ela se sustentou com o jornalismo. Anteriormente, como ela possui uma primeira formação em Secretariado, ela alternou em funções administrativas.

Era, mas no momento eu não estou produzindo. Ano passado chegou a parceria com o Bora [SP] e eu cheguei a fazer alguns vídeos e aí é assim, se você produz você tem, se você não produz, não. Aí eu entro em uma espiral de desânimo, de falta de interesse e aí eu paro de ir à reunião, paro de ver coisas por aqui, paro de escrever, paro de gravar, paro de receber, mas aí a vida continua. Há um tempo eu tenho procurado emprego na área administrativa, tenho tentado voltar para essa área. Às vezes eu penso que um momento de vida que eu tenho saudades é da época que eu conciliava a Mural com um emprego, que era uma coisa extra, não uma coisa da qual eu tinha que fazer, tinha uma outra relação. Eu saí da outra área em 2013 para tentar mudar de área, tentar alguma outra coisa e no fim eu nem consigo ir para a área e nem consigo voltar para onde eu estava, parece que eu caí em um buraco. Eu fiquei de setembro de 2013 até fevereiro de 2016, quase três anos, eu consegui uma vaga administrativa e que era um contrato de um ano e eu não passei da experiência, fiquei três meses. Saí de lá em julho de 2016,

Revista ALTERJOR

Grupo de Estudos Alterjor:Jornalismo Popular e Alternativo (ECA-USP)

Ano 10 Volume Ol Edição 23 Janeiro-Junho de 2021

Avenida Professor Lúcio Martins Rodriġues, 443, Cidade Universitária, São Paulo, CEP: 05508-020 
foi o ano que meu pai morreu, que deu uma bagunçada na minha vida, na minha cabeça, as coisas já não estavam legais e desde então eu não consigo mais emprego formal. Durante um tempo eu auxiliei nas redes da Mural, de julho de 2017 a julho de 2018, desde então eu estou tentando alguma vaga por aqui. Eu ando bem desanimada com as coisas e aí por isso eu vi essa faculdade EAD da Univesp, desse curso de pedagogia, pensando em tentar outra coisa, tentar educação (entrevistada C).

- A situação da entrevistada C mostra que não se manter apenas do coletivo traz um desafio, que é conseguir se manter de outra forma, ou aumentar o ritmo de produção para receber mais no final do mês. É mais produzir pela necessidade do que pela vontade protagonizar grandes transformações, e com quem fica o direito a ser alternativo? Ela também comenta que trabalharia em um veículo tradicional, se tivesse a oportunidade.

- A entrevistada D comenta que a Agência Mural complementa sua renda junto com outros freelas e que houve uma época em que ela migrou para a área de vendas, mas no geral sempre se sustentou com o jornalismo. Ela também trabalharia na grande mídia se houvesse oportunidade e diz que ainda tenta um emprego "na área". Questionamos se ela não considerava já estar na área, mas ela acredita que está em partes.

Eu estou, mas não tão diretamente. Eu sou freela, então acho que não estou tão ativamente como na grande mídia, que você está lá todo dia, se aprimorando. Eu estou batalhando, vendo pautas, vendo o que acontece no meu bairro e sugiro pautas que podem ser aprovadas ou não, mas lutando para conquistar um espaço. Sim, com certeza trabalharia [na mídia tradicional], porque eu desenvolveria mais o jornalismo, financeiramente também é legal. Estar ali full time, fazendo o jornalismo todo dia, tendo ideias, e também fazendo outras editorias, conseguindo uma pluralidade na grande mídia. Produzir também matérias grandes, gerar um impacto maior (entrevistada D).

- Já a entrevistada E tentou por um tempo se manter de jornalismo, mas não conseguiu. Ela disse que justamente por não escrever tão rápido, não conseguia produzir tanto e o dinheiro não entrava, por isso hoje ela se mantém também com projetos culturais que realiza na região em que mora. Sobre trabalhar na grande imprensa, ela aceitaria, mas dependeria do veículo.

Trabalharia na TVT, agora se fosse a Globo, aí é uma questão de história de vida. Eu bati muito na Globo nesse movimento anarco-punk, então não dá para entrar na Globo, é muita contradição. Vai muito de uma linhagem. Se eu pudesse ter uma liberdade como eu tenho na Mural eu trabalharia sim, mas dependeria também do veículo e seu posicionamento, mesmo quando diz que é neutro, como o Estadão, aí não daria. Mesmo a parceria com a Band, é complicado, mas ao mesmo tempo temos liberdade nos vídeos, nas pautas, para fazer da maneira que a gente quer. Então algumas mídias eu toparia, se mantivesse a liberdade de eu escrever o que quero (entrevistada $\mathrm{E}$ ).

Revista ALTERJOR

Grupo de Estudos Alterjor:Jornalismo Popular e Alternativo (ECA-USP)

Ano 10 Volume Ol Edição 23 Janeiro-Junho de 2021

Avenida Professor Lúcio Martins Rodrig̉ues, 443, Cidade Universitária, São Paulo, CEP: 05508-020 
$\mathrm{Na}$ fala da entrevistada E é possível identificar traços fortes de militância e ideologias alinhadas, que foram motores importantes para despontar o jornalismo alternativo no Brasil. Essa militância auxiliou na criação de diversas mídias contrahegemônicas que, mais tarde, seriam primordiais para diversas experiências de novas maneiras de mídia, como as sindicais.

Os entrevistados A e B concordam que o surgimento de iniciativas em cenários desfavoráveis do mercado jornalístico pode gerar novas mídias, novos arranjos e que podem oferecer novas possibilidades aos jornalistas. Apesar da crise da área, é sempre uma possibilidade de se nascer algo novo:

Acho que o jornalismo sempre vai existir, que as pessoas vão consumir, mas precisamos procurar novos jeitos de fazer o jornalismo. Essa nova geração, acredito que vai produzir cada vez mais jornalismo alternativo e vai criar maneiras de produzir as notícias. Acho que os coletivos são muito importantes para o jornalismo alternativo da periferia porque só assim para coisas acontecerem mesmo. Um veículo de mídia hegemônico nunca vai entrar na favela com os mesmos propósitos que um coletivo entraria, mas como disse no começo, o grande desafio entre empresa e produto jornalístico, também é muito latente nesses coletivos. Talvez não desde o começo, mas chega um momento, de acordo com a relevância que ele vai conquistando, essa hora chega, você tem que encarar isso de frente, precisa de maturidade e não são em muitos coletivos que vejo isso, mas isso vem com o tempo. Querendo ou não, em termos históricos, toda essa onda de coletivo e mídias alternativas começou ontem. Então acho que ainda leva um tempo (entrevistada A).

\section{O entrevistado B complementa que:}

As redações estão bem mais enxutas e talvez isso dificultou ainda mais a cobertura sobre outras regiões da cidade de São Paulo. Ao mesmo tempo, temos muitas iniciativas acontecendo. De um lado temos esse modelo de jornalismo que tenta se manter como negócio e pessoas que saíram dele e montaram outros negócios, outros veículos. Então, temos com a internet uma série de veículos que surgiram e uma série de oportunidades que possibilitam novos canais e outras oportunidades. Ainda é um mercado difícil, que você tem que provar a cada dia seu potencial, mas acho interessante esse movimento. Antes você só tinha um jornal, poucos lugares para trabalhar, mas hoje você pode fazer coisas muito interessantes com o surgimento de novos veículos, e esses veículos surgiram muito com a saída desses profissionais de grandes redações. Acho que isso é um movimento até bom, pois se acabou difundindo mais a informação. Só é mais complicado, porque nem todos ainda conseguem formas de financiamento e encontrar formas de se financiar e financiar esse trabalho (entrevistado B). 
Em todos os entrevistados, a preocupação acaba sendo semelhante: maneiras de financiamento. Apesar de crerem estar fazendo um trabalho importante para a comunidade e até mesmo para o jornalismo, com novas formas de cobertura e mais espaço e modelos de produção, com mais espaços jornalísticos e uma menor concentração das mídias, a questão monetária complica ainda mais a precarização dos jornalistas que vêm das periferias.

Ainda sobre o mercado de trabalho, a entrevistada $\mathrm{C}$ fala que as mudanças que diversas áreas vêm passando nos últimos anos, afeta muito mais quem já está no mercado há mais tempo:

Eu fiz jornalismo de 2008 a 2011 e a gente está em 2020, eu tenho quase 10 anos de formada e muita coisa aconteceu nesse período. Eu fico pensando sobre a formação acadêmica que a gente tem, a oportunidade, o aprendizado, em relação à estágio e hoje tem muito essa coisa do faça você mesmo [...] Então, algumas deficiências durante a formação, não só de responsabilizar a universidade, mas de assumir uma responsabilidade também, tipo, eu deveria ter pegado mais pesado, feito um curso extra, mas também tem a questão de preço, que são coisas que não são baratas [...] Algumas profissões estão mudando, umas desaparecendo, outras surgindo e como a gente se coloca no meio disso, por que o que será que vem pela frente? Com máquinas, computadores, sistemas que podem substituir o jornalista e etc (entrevistada C).

A fala da entrevistada $\mathrm{C}$ se assemelha com o depoimento da entrevistada $\mathrm{A}$, que preferiu não fazer estágios também na época da faculdade por só encontrar oportunidades em Assessoria de Imprensa. As mudanças, principalmente no modelo de trabalho, como as contratações por contrato de $\mathrm{PJ}$, acabam por prejudicar muito mais quem não pode apenas depender de freelas, mas ainda assim precisa adquirir experiência, um dos problemas enfrentados por diversos profissionais que estão em arranjos econômicos, seguindo ainda de forma precarizada (NONATO, 2018).

A entrevistada D complementa com sua visão de como a escassez de vagas fixas assola o jornalismo, fato que implica em pessoas com maior experiência aceitando vagas de recém-formados apenas para continuar dentro da área. Assim como citou acima a entrevistada C, o impacto das mudanças digitais afetou o fazer jornalístico e quem o faz: 
A digitalização e a convergência das plataformas digitais com os veículos impressos têm piorado as condições de trabalho, uma vez que os jornalistas são obrigados a assumir papéis e funções adicionais, como adaptar conteúdo do impresso para o fornecimento digital, muitas vezes sem serem pagos pelo trabalho extra. Alguns jornalistas, apesar de reconhecerem as oportunidades oferecidas pela digitalização, destacam que suas condições de trabalho foram negativamente impactadas ao longo da última década, uma vez que são obrigados a fazer horas extras e a assumir novas funções para atender às demandas resultantes do fornecimento de notícias em formato digital (MIZUKAMI, REIA e VARON, 2014, p. 78).

A entrevistada E concorda que o mercado de trabalho do jornalista está difícil e que a área que mais contrata ainda é a Assessoria de Imprensa:

Está difícil. Eu tenho um problema com assessoria de imprensa, principalmente das empresas que eu não acredito, mas infelizmente é onde mais se abrem portas para alguns trabalhos, né? Eu acho que a carreira atrapalha muito isso. Eu penso em largar os projetos e trabalhar com assessoria, mas com os projetos eu ainda tenho algo que eu acredito, então eu sempre fico pensando na dificuldade de o jornalista sobreviver e sobreviver fazendo aquilo que ele acredita, acho que isso é uma crise. E tem o lance de não ter vínculo, como a maioria das redações que não tem vínculo empregatício com o jornalista e aí isso faz a pessoa pirar mesmo, porque ela vai fazendo mil coisas para dar conta de pagar os boletos e isso acaba sucateando a profissão. Acho que tínhamos que voltar a ter uma organização que garantisse o mínimo dos direitos. Acho que a humanização com a profissão do jornalista está cada vez mais distante, e acho que a Mural e outras agências estão tentando cada vez mais fazer isso, mas são poucas iniciativas ainda se compararmos com o padrão que vem de cima para baixo. Tem essas iniciativas que enchem o coração de esperança (entrevistada E).

A entrevistada $E$ fala de um problema comum e que levantamos ao longo dos resultados. Muitos jornalistas buscam trabalhar com um propósito. Realizar um trabalho que realmente impacte sua sociedade, sua comunidade e sua realidade. Infelizmente não há espaço para todos. Como Mick (2015) apontou em seu artigo "entre 1990 e 2010, o número de cursos superiores de Jornalismo quintuplicou, de 61 a 317”. De acordo com o autor, a grande oferta de profissionais qualificados favoreceu que empresas de mídia ou mesmo as não-midiáticas, usassem essa mão de obra qualificada para fins que servissem seus próprios interesses. Daí, muitos jornalistas formados acabaram por buscar e se encontrar em outras profissões (MICK, 2015).

A entrevistada $\mathrm{C}$ questiona o conceito de liberdade e o problematiza com as percepções de mercado de trabalho.

Revista ALTERJOR

Grupo de Estudos Alterjor:Jornalismo Popular e Alternativo (ECA-USP)

Ano 10 Volume Ol Edição 23 Janeiro-Junho de 202l

Avenida Professor Lúcio Martins Rodrig̉ues, 443, Cidade Universitária, São Paulo, CEP: 05508-020 
É meio louco falar de liberdade hoje, né? Porque, o que a liberdade está significando em um país que está aprovando reformas para acabar com os direitos trabalhistas, qual o preço da liberdade? É pedalar o dia inteiro, mas aí se você ficar doente, foda-se. É fazer texto para um lugar, para dois, para três, então a gente está vivendo muito o hoje, pagando boleto de hoje, comendo a marmita de hoje, mas como vai ser o futuro para essa galera alternativa que não tem uma previdência? Ou é porque a gente vai morrer cedo mesmo, o coração não vai aguentar? É muito complexo. Às vezes, dependendo da idade, por exemplo, como eu que entrei no jornalismo como segunda faculdade, talvez se eu tivesse entrado em jornalismo lá em 2003, talvez eu não tivesse essa fixação de ser CLT. Às vezes a gente se compara muito com os outros e eu percebi que, como eu já era CLT, eu não queria, não tinha uma pressão familiar também e eu via que as pessoas faziam estágio, não tinham vínculo e estava ok, ia levando. Quem entra em uma faculdade de alguns anos para cá, entra, faz um estágio, depois vai ser MEI, alguma coisa. Parece que as pessoas mais jovens se adaptam e eu tenha entrado em um negócio com quase 30 anos, sem querer mudar e eu estou ficando para trás, às vezes é a impressão que eu tenho. Quando a gente não estagia na área fica mais complicado, mas ao mesmo tempo tem gente que nem entrou em uma Mural, que não fez estágio, não fez nada.

Eu acho que não [não impacta a notícia], vai do jogo de cintura de cada um. Porque assim, eu não trabalho, eu poderia estar indo atrás de pautas, mas eu não estou sentindo vontade. Às vezes eu vejo que a pessoa trabalha e a pessoa está a fim de fazer, às vezes no dia da folga a pessoa vai atrás de alguma coisa, tem uma alegria naquele fazer. Eu acho que tem uma coisa que faz diferença, por exemplo, algumas pessoas têm um pouco de militância. Quando eu olho, o que eu mais produzi foi referente a território (entrevistada C).

A fala da entrevistada $\mathrm{C}$ nos leva a problematizações da área presentes em diversas discussões teóricas e demonstra as principais fragilidades entre as relações de trabalho e a sustentabilidade financeira dos coletivos. Como garantir a liberdade editorial, o propósito, a ideologia e ainda manter uma condição econômica minimamente estável? A crise que atinge o jornalismo há alguns anos, com precarização e flexibilização de contratos trabalhistas, acúmulo de funções, entre outras demandas, se estende e acomete ainda mais os coletivos alternativos ou arranjos econômicos.

Citamos mais uma vez a pesquisa "As relações de comunicação e as condições de produção no trabalho de jornalistas em arranjos econômicos alternativos às corporações de mídia" (FÍGARO, 2018), realizada pelo CPCT-ECA/USP, sobre as condições de diversos coletivos ou arranjos econômicos, após entrevistas com seus integrantes. 


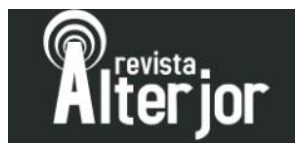

A pesquisa confirma as complicações enfrentadas pelos veículos alternativos ao mesmo tempo em que buscam realizar um jornalismo que se distancie dos interesses comerciais da grande mídia. Muitos desses jornalistas realizam trabalhos voluntários, sem ter certeza de quando vão receber e, como a entrevistada $C$ pontuou, acabam por produzir para mais que um local no objetivo de compor uma renda mensal.

Há também a intensificação do trabalho, já que muitos dos jornalistas precisam manter seus empregos em outros locais e, após isso, dedicar-se ao seu trabalho no arranjo, desempenhando uma dupla função. Os coletivos ou arranjos que conseguem se manter sem a necessidade de outras rendas ainda são poucos e sua receita não advém da produção jornalística que realizam, mas de outras rendas como editais da prefeitura, venda de serviços ou aportes de fundações como a Fundação Ford e a Open Society, e financiamentos recorrentes, no estilo crowdfunding (FÍGARO, 2018).

\section{CONSIDERAÇÕES FINAIS}

Ao realizar as entrevistas com alguns integrantes da Agência Mural, notamos que, ainda, as principais dificuldades citadas são segurança financeira, estabilidade e até mesmo a falta de pertencimento e identificação com uma espécie de trabalho, como comentou a entrevistada $\mathrm{C}$, que não considera que atua na área.

É inegável a importância de coletivos como o a Agência Mural, que apresenta uma cobertura diferenciada dos fatos que acontecem na periferia, buscando contar histórias que fogem dos estereótipos da mídia, ao mesmo tempo que também potencializa a voz desses moradores, cobrando o poder público das mais variadas demandas, mas sem entregar o olhar de "pobres coitados da favela".

Entretanto, é importante chamar a discussão desse tema, pois como fica a segurança financeira desses jornalistas? Como fica a dedicação à luta quando sua preocupação é garantir o aluguel no final do mês? É natural se desdobrar em mais de uma ocupação para garantir o sustento e as mudanças em sua comunidade? Pois bem, não deveria. Esses jornalistas que já enfrentaram as mais diversas dificuldades apenas para conseguir um diploma, encontram outras mil ao tentar adentrar na área, que muitas 


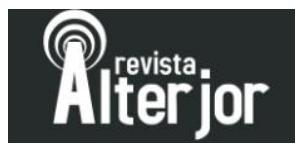

vezes não representa seus verdadeiros desejos, não é dessa forma que eles desejam passar sua ideia. Então eles criam iniciativas, apoiam lideranças, participam de projetos, multiplicam vozes para transformar as margens das quais vieram, mas ainda sofrem com a falta de retorno, muito injusto, dentro da profissão.

É importante traçar novas possibilidades de financiamento, de trabalho, de valorização, pois senão os coletivos repetirão as mesmas fórmulas das grandes empresas que tanto discriminam e negam quem veio da periferia: a falta de oportunidades e a má remuneração. Ainda não temos a solução para o problema, mas é urgente que o debate se faça presente, gerando discussões que, juntas, possam transformar a carreira desses jornalistas.

\section{REFERÊNCIAS}

AGÊNCIA MURAL. Sobre. < https://www.agenciamural.org.br/>

AGÊNCIA PÚBLICA. Mapa do jornalismo independente. 2016 < https://apublica.org/mapa-do-jornalismo/>

ASSIS et. al. Autonomia, ativismo e colaboração: contribuições para o debate sobre a mídia independente contemporânea. Revista Pauta Geral-Estudos em Jornalismo. Ponta Grossa, vol. 4, n.1, p.3 - 20, Jan/Jun 2017.

BONI, Valdete; QUARESMA, Sílvia Jurema. Aprendendo a entrevistar: como fazer entrevistas em Ciências Sociais. Revista Eletrônica dos Pós-Graduandos em Sociologia Política da UFSC vol. 2, no, janeiro-julho/2005, p. 68-80.

CARVALHO, G. BRONOSKY, Marcelo. Jornalismo alternativo no Brasil: do impresso ao digital. Pauta Geral - Estudos em Jornalismo. Vol. 4, no 1, 2017, p. 21 a 29.

DUARTE, Rosália. Entrevistas em pesquisas qualitativas. In: Educar, Curitiba, n. 24, p. 213-225, 2004. Editora UFPR.

FIGARO, Roseli (Org.). As relações de comunicação e as condições de produção no trabalho dos jornalistas em arranjos econômicos alternativos às corporações de mídia. São Paulo: ECA-USP, Centro de Pesquisa Comunicação e Trabalho, 2018.

HAGUETTE, Teresa Maria Frota. Metodologias qualitativas na Sociologia. 5a edição. Petrópolis: Vozes, 1997.

Revista ALTERJOR

Grupo de Estudos Alterjor:Jornalismo Popular e Alternativo (ECA-USP)

Ano 10 Volume Ol Edição 23 Janeiro-Junho de 2021

Avenida Professor Lúcio Martins Rodrig̉ues, 443, Cidade Universitária, São Paulo, CEP: 05508-020 


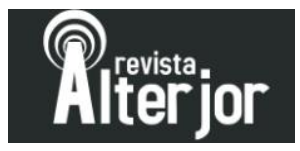

INFANTE, Maisa. Aqui, a periferia é o centro do negócio: como a Agência Mural evoluiu de blog para agência de notícias. Disponível em: https://www.projetodraft.com/aqui-a-periferia-e-o-centro-do-negocio-como-a-agenciamural-evoluiu-de-blog-para-agencia-de-noticias/. Acesso em: 25/10/2020.

KUCINSKI, Bernardo. Jornalistas e revolucionários. Nos tempos da imprensa alternativa. 2 ed., revista e ampliada, São Paulo: Edusp: 2001.

LOUREIRO, Eliana Regina Lopes; CASADEI, Eliza Bachega. "Isso a Globo não mostra": dimensões afetivas das notícias falsas no debate sobre o descrédito da imprensa tradicional. In: CONGRESSO DA ASSOCIAÇÃO BRASILEIRA DE PESQUISADORES EM COMUNICAÇÃO E POLÍTICA - COMPOLÍTICA, 8, 2019, Brasília. Anais do 8 o Compolítica. Brasília: Compolítica, 2019. Disponível em: http://ctpol.unb.br/compolitica2019/GT4/gt4_Loureiro_Casadei.pdf. Acesso em 6 out. 2019.

MICK, J.; LIMA, S. Perfil do jornalista brasileiro: características demográficas, políticas e do trabalho jornalístico em 2012. Disponível em: https://perfildojornalista.ufsc.br/files/2013/04/Perfil-do-jornalista-brasileiro-Sintese.pdf

NONATO, Cláudia. Da redação aos blogs: a busca por novos arranjos econômicos e alternativas ao trabalho jornalístico. In: Revista Famecos - Mídia, Cultura e Tecnologia, Porto Alegre, v. 25, n. 1, p. 1-21, jan./abr. 2018.

SANTOS, Pedro Lucas Oliveira. Imprensa Alternativa: discutindo o conceito. Revista ALTERJOR, São Paulo, ano 04, vol. 02, edição 08, julho-dezembro de 2013.

SILVA, Geilson dos Santos. Formas de financiamento e sustentabilidade do jornalismo alternativo no ambiente digital: as experiências da Agência Mural e da Marco Zero. Dissertação (Programa de Pós-graduação em Comunicação) - Universidade Federal de Sergipe, São Cristóvão, 2018. 